\title{
Aerosol delivery during invasive mechanical ventilation: a systematic review
}

\author{
Jonathan Dugernier ${ }^{1,2,3^{*}} \mathbb{D}$, Stephan Ehrmann ${ }^{4,5,6}$, Thierry Sottiaux', Jean Roeseler ${ }^{2}$, Xavier Wittebole ${ }^{2}$, \\ Thierry Dugernier ${ }^{8}$, François Jamar ${ }^{9}$, Pierre-François Laterre ${ }^{2}$ and Gregory Reychler ${ }^{1,3,10}$
}

\begin{abstract}
Background: This systematic review aimed to assess inhaled drug delivery in mechanically ventilated patients or in animal models. Whole lung and regional deposition and the impact of the ventilator circuit, the artificial airways and the administration technique for aerosol delivery were analyzed.

Methods: In vivo studies assessing lung deposition during invasive mechanical ventilation were selected based on a systematic search among four databases. Two investigators independently assessed the eligibility and the risk of bias.

Results: Twenty-six clinical and ten experimental studies were included. Between 30\% and 43\% of nominal drug dose was lost to the circuit in ventilated patients. Whole lung deposition of up to $16 \%$ and $38 \%$ of nominal dose (proportion of drug charged in the device) were reported with nebulizers and metered-dose inhalers, respectively. A penetration index inferior to 1 observed in scintigraphic studies indicated major proximal deposition. However, substantial concentrations of antibiotics were measured in the epithelial lining fluid $(887(406-12,819) \mu \mathrm{g} / \mathrm{mL}$ of amikacin) of infected patients and in sub-pleural specimens (e.g., $197 \mu \mathrm{g} / \mathrm{g}$ of amikacin) dissected from infected piglets, suggesting a significant distal deposition. The administration technique varied among studies and may explain a degree of the variability of deposition that was observed.

Conclusions: Lung deposition was lower than $20 \%$ of nominal dose delivered with nebulizers and mostly occurred in proximal airways. Further studies are needed to link substantial concentrations of antibiotics in infected pulmonary fluids to pulmonary deposition. The administration technique with nebulizers should be improved in ventilated patients in order to ensure an efficient but safe, feasible and reproducible technique.
\end{abstract}

Keywords: Nebulizer, Antibiotics, Bronchodilators, Scintigraphy

\section{Background}

Aerosol therapy is commonly used in the intensive care unit. Three primary classes of drugs are delivered by inhalation to mechanically ventilated patients: bronchodilators, corticosteroids and antibiotics [1]. Drug efficacy depends on the dose and the site of deposition. The clinical benefit of bronchodilators plateaus the effective dose is deposited, and increasing the dose will expose the patient to potential adverse events (e.g., cough, tachycardia and tremor) [2, 3].

\footnotetext{
* Correspondence: Jonathan.dugernier@uclouvain.be

${ }^{1}$ Institut de Recherche Expérimentale et Clinique (IREC), Pneumologie, ORL \&

Dermatologie, Cliniques universitaires Saint-Luc, Avenue Hippocrate 10, 1200 Brussels, Belgium

${ }^{2}$ Soins Intensifs, Cliniques universitaires Saint-Luc, Avenue Hippocrate 10,

1200 Brussels, Belgium

Full list of author information is available at the end of the article
}

With respect to inhaled antibiotics, concentrations should be maximized at the infected lung site to obtain an effective bactericidal effect according to their pharmacokineticspharmacodynamics characteristics [4].

Many factors influence aerosol delivery to the lungs during mechanical ventilation and are related to the drug, the device, the patient, the ventilator circuit, the artificial airways and the ventilator settings [5]. These factors have been primarily studied in vitro [6-8]. During the past 30 years, clinical and experimental studies have investigated lung deposition of inhaled drugs during invasive mechanical ventilation using imaging techniques based on radiolabeled aerosol deposition, lung tissue sampling and pharmacokinetics analysis $[5,9,10]$. A comprehensive systematic review summarizing in vivo 
data related to aerosol delivery during invasive mechanical ventilation has never been published.

The aim of this review is to evaluate studies that assessed in vivo lung delivery of inhaled drugs to mechanically ventilated patients or animal models either as absolute drug concentrations or quantitative deposition relative to the nominal dose to: (1) provide current knowledge on whole lung deposition; (2) examine the distribution and penetration of inhaled drugs into different regions of the respiratory tract; (3) determine how the ventilator circuit and the artificial airways impact aerosol delivery and (4) discuss the administration techniques applied in these studies.

\section{Methods}

This study was registered in the International Prospective Register of Systematic Reviews (PROSPERO CRD42016047186) and was conducted according to the Preferred Reporting Items for Systematic Reviews and Meta-Analyses (PRISMA) guidelines [11].

\section{Search strategy and data extraction}

The search strategy, selection criteria, data extraction and study quality assessment are detailed in Additional file 1 . The systematic search was performed among the Pubmed, Science Direct, Scopus and PeDRO database by one investigator (JD) who examined publications from 1985 to Sept 2016. Original research articles were included according to inclusion criteria based on participants, interventions, comparisons, outcomes and study design (PICOS) (Table 1). Articles published in a language other than English and French, were excluded. The Downs and Black scale was used to define the methodological quality of eligible studies [12].

\section{Data expression}

The data were expressed as the mean \pm standard deviation or median (25-75\% interquartile range). Lung deposition data were expressed as percentage of nominal dose (\% ND, i.e., the amount of drugs placed in the reservoir of the nebulizer or contained in the puffs of the metered-dose inhaler at the beginning of experiments) or as percentage of inhaled dose (\% ID, i.e., the amount of drugs that reach the distal tip of the artificial airways). The penetration of the aerosol particles into the lungs was evaluated by the penetration index. The penetration index was calculated using the outer to the inner lungdeposition region ratio normalized to the lung volume as described previously [13]. The inter-subject variability for the lung deposition data was characterized using the coefficient of variation ( $\mathrm{CV}$, expressed as a percentage) or the dispersion around the median.

\section{Results}

The flow diagram for study selection is depicted in Fig. 1 . Among 234 articles assessed for eligibility, 36 studies were included and comprised 26 clinical studies (see Additional file 2: Table S1) [14-38] and 10 experimental studies (see Additional file 2: Table S2) [39-48]. The Downs and Black scores were $20 \pm 2$ and $18.5 \pm 0.5$ for the clinical and experimental studies, respectively (see Additional file 2: Table S3). Twenty clinical studies evaluated critically ill ventilated patients who were specifically suffering from documented nosocomial lung infection (ventilator-associated tracheobronchitis (VAT) or ventilator-associated pneumonia (VAP)) or were ventilated for others reasons such as chronic obstructive pulmonary disease (COPD), acute respiratory distress syndrome (ARDS) or other types of respiratory infection. Six studies were performed in ventilated patients without critical illness. These patients had lung cancer or were in the postoperative phases following cardiac, abdominal or neurological surgery. Experimental studies were performed in ventilated piglets ( 9 of 10 studies) or dogs ( 1 of 10 studies). Two thirds of the studies included in this systematic review were comparative (25 of 36 studies) (different populations, devices or administration techniques), and most were not randomized (18 of 25 studies) and were nonblinded (21 of 25 studies). Only 6 of 36 studies reported a sample size calculation, which varied from 5 to 69 patients and from 6 to 36 animals $[15,18,20,24,34,38]$. Lung delivery was assessed using mass balance techniques, lung tissue sampling, imaging or pharmacokinetics techniques in 9, 9, 10 and 16 studies, respectively. Drugs of interest are detailed in Table 2.

Table 1 Inclusion criteria for studies according PICOS

\begin{tabular}{ll}
\hline Participants & Adult aged 18 years or older with invasive mechanical ventilation \\
Interventions & or in vivo experimental model of adult invasive mechanical ventilation \\
& Aerosol administration using any type of device (nebulizer, metered-dose inhaled, dry powder inhaler, etc.) \\
Outcomes & Aerosol deposition assessment using pharmacokinetics or radioisotopic methods \\
& Pulmonary deposition of inhaled drug (dose, distribution or penetration) \\
Study designs & Extrapulmonary deposition, if available \\
\hline
\end{tabular}




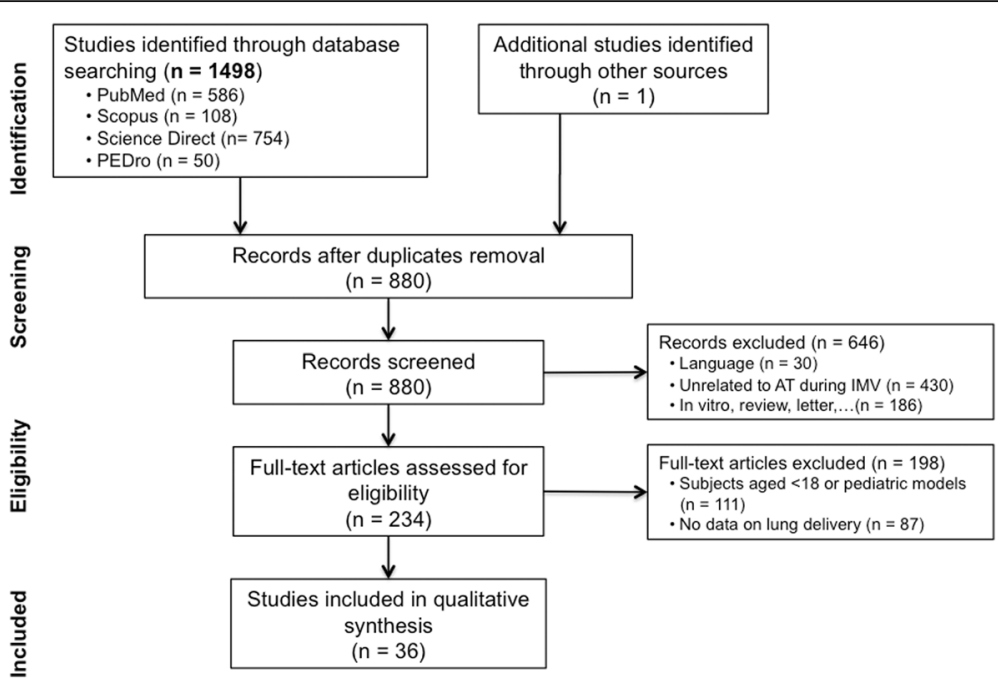

Fig. 1 Flow diagram for study selection according to Moher et al. [11] AT aerosol therapy, IMV invasive mechanical ventilation

\section{Drugs reaching the distal tip of artificial airways}

Using the mass balance technique (i.e., rinsing of the ventilator circuit), authors reported $22 \%$ to $66 \%$ ND antibiotics reaching the distal tip of the tracheostomy cannula or the endotracheal tube [36, 39, 41-46, 48]. Imaging deposition studies revealed that the trachea and large bronchi represent the major site of drug deposition (Fig. 2) [18, 25, 29, 35, 37]. The study by Klockare et al. [24] reported a 49\% ID of radiolabeled drug deposited in the trachea and the main bronchi of nine critically ill patients whereas $51 \%$ was distributed in both lungs with $14 \%$ in the lobar and segmental bronchi using single photon emission tomography combined with a computed tomography scanner (SPECT-CT).

\section{Aerosol delivery to the lungs}

The highest drug doses deposited into the lungs (from the hili to the periphery, 38\% ND) were obtained using a metered-dose inhaler (MDI) combined with an inhalation chamber at the Y-piece [30]. Lung doses from 3 to 7\% ND and 1 to $16 \%$ ND were reported with constant-output jet nebulizers $[25,29]$ and inspiratory synchronized jet nebulizers $[19,22,23,29,37]$ whereas a 5\% ND was reported with a constant-output ultrasonic nebulizer [23]. Only one scintigraphic study assessed aerosol delivery in patients using a constant-output vibrating-mesh nebulizer and measured lung doses of only 10-15\% ND [18].

\section{Aerosol distribution between both lungs}

Two studies comparing aerosol delivery using a constantoutput UN or direct instillation in the endotracheal tube observed a more homogeneous distribution of drugs with a nebulizer [15, 24]. Using SPECT-CT, Klockare et al. [24] measured 33\% and 17\% ID of radiolabeled drug in the right and the left lung after aerosol administration compared with $67 \%$ and $7 \%$ ID after instillation. A similar distribution of radiolabeled drug was measured in both lungs of patients post neurosurgery, with a trend towards a greater right to left lung-deposition ratio (from 1.39 to 3.33) [18]. Four studies enrolling critically ill or postoperative patients following open-heart surgery observed a lower left lung deposition in comparison with that of the right lung [22-24, 37].

\section{Aerosol penetration into the lungs}

Ferrari et al. [41] reported 10\% ND ceftazidime in subpleural specimens (i.e., homogenized bronchioles and alveoli) of healthy piglets whereas 50\% ND was deposited into the trachea and proximal airways. Similar concentrations of amikacin were measured in sub-pleural

Table 2 Drugs of interest

\begin{tabular}{ll}
\hline & Drugs \\
\hline Antibiotics & Amikacin and amikacin sulfate [27, 28, 32, 34, 39, 40,43,44, 49], colistin or colistimethate sodium [14, 16, 46], \\
& ceftazidime [38, 41, 42, 48, 49], pentamidine [21], gentamycin [31, 36], tobramycin [15, 25], vancomycin [31], \\
& fosfomycin [32], imipenem [15] or teicoplanin [45] \\
Tracer labeled with & Diethylenetriaminepentaacetic acid [18, 24, 25, 29], pertechnetate [19], sulfur colloid [19], albumin [22, 23, 35, 37] \\
technetium-99 $\mathrm{m}$ & or fenoterol [20] \\
Bronchodilators & Albuterol [17, 30], fenoterol [20] or ipratropium bromide [26, 33] \\
Other & Cisplatin [47] \\
\hline
\end{tabular}



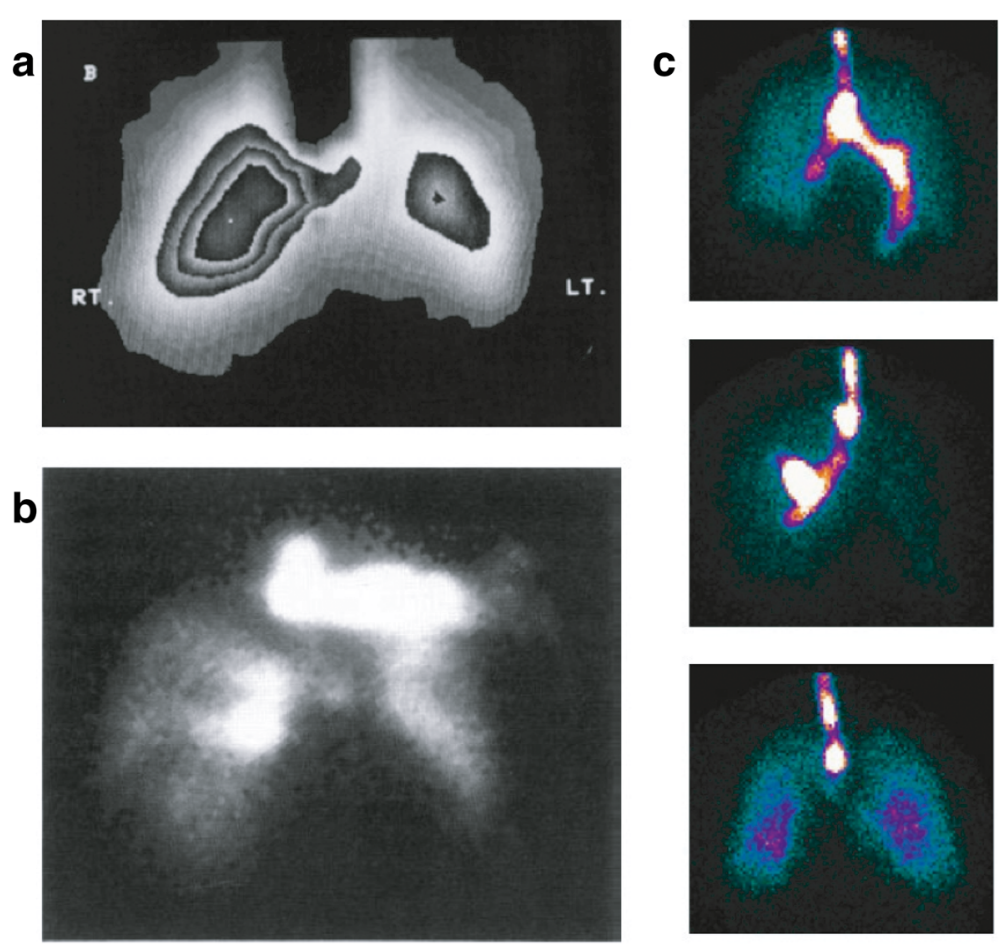

Fig. 2 Anteroposterior acquisition using planar scintigraphy for radiolabeled aerosol deposition assessment in an intubated patient after open-heart surgery (from Thomas et al. [37], with permission) (a), a tracheotomised critically ill patient (from O'Riordan et al. [35], with permission) (b) and three intubated neurosurgical patients ventilated in volume control mode (from Dugernier et al. [18] with permission) (c). Even if lung outlines suggested that inhaled drugs reached the lung periphery, these images illustrate that the majority of drugs impacted proximally in the artificial airways and particularly in the trachea and large bronchi. High deposition in the endotracheal tube, the trachea and the main bronchi has been masked to improve lung definition (a)

specimens from both lungs, different lobes and dependent and nondependent regions from the lower lobes of healthy piglets on the first day of intubation [44]. However, a significant reduction in concentrations in dependent lung regions after prolonged mechanical ventilation was observed (50 to $400 \mu \mathrm{g} / \mathrm{g}$ after $24 \mathrm{~h}$ vs 20 to $60 \mu \mathrm{g} / \mathrm{g}$ after $72 \mathrm{~h}$ of mechanical ventilation, $p<0.05$ ) [40]. Moreover, five studies of infected piglets showed a significant reduction of antibiotic deposition in subpleural specimens of lung regions with severe bronchopneumonia characterized by a massive aeration loss in comparison with partially aerated lung regions with mild bronchopneumonia [39, 42, 43, 46, 48].

Postoperative scintigraphic studies reported a penetration index (normalized $\mathrm{O} / \mathrm{I}$ ratio) in patients of 0.32 to 0.75 , which indicated a predominant proximal deposition [18, 37]. Eight pharmacokinetics studies reported a significant amount of antibiotics in tracheal secretions and substantial epithelial lining fluid (ELF) concentrations $[14,15,27,28,31,32,34,36]$.

\section{Variability in lung deposition}

The intersubject variability of lung deposition ranged from 9 to $62 \% \mathrm{CV}$ in the scintigraphic studies whatever the device used (nebulizers or metered-dose inhalers) [18-20, 22, 23, 29, 35, 37]. Dugernier et al. [18] reported a wide variability in the right to left lung-deposition ratio (3.33 (0.7-5.38) in VCV and 1.39 (0.91-2.05) in PSV). The penetration index also varied among subjects with a CV of approximately $50 \%[18,37]$. Pharmacokinetics studies observed from 14 to $85 \% \mathrm{CV}$ of antibiotic concentrations in tracheobronchial secretions [31, 32, 34, 36] and from 60 to $91 \%$ CV in ELF $[14,15,27,28]$.

\section{Deposition in the ventilator circuit, artificial airways and nebulizer retention}

Fifteen studies measured drug retention within nebulizers and the circuit $[18,22,23,29,35,37,39,41-46$, $48,49]$. No data on aerosol loss with MDIs have been described. Drug doses retained in the nebulizer reservoir and the T-piece were approximately $50 \% \mathrm{ND}$ with jet nebulizers, $15 \%$ to $30 \%$ ND with ultrasonic nebulizers and $3 \%$ to $10 \% \mathrm{ND}$ with vibrating-mesh nebulizers. While drugs deposited in the artificial airways and/or the trachea and the main bronchi varied from 1 to $27 \%$ $\mathrm{ND}$, drugs trapped in the ventilator circuit varied from $10 \%$ to $44 \%$ ND. Drug loss during expiration was 7 to $22 \%$ ND (Fig. 3). 


\section{Administration technique}

Vibrating-mesh nebulizers are preferred over jet and ultrasonic nebulizers to deliver antibiotics (50\% vs 18 and $32 \%$ of inhaled antibiotics studies, respectively). Vibratingmesh and ultrasonic nebulizers demonstrated similar efficacy in 10 healthy piglets [41]. On one hand, greater postoperative efficacy of ultrasonic nebulizers compared to jet nebulizers was suggested in seven patients [23]. On the other hand, Lee et al. [26] did not report higher efficacy for a recent vibrating-mesh nebulizer compared to a conventional jet nebulizer. However, the authors measured $46 \% \mathrm{ND}$ in the T-piece of the vibrating-mesh nebulizer, which questioned its efficiency in generating aerosol particles [26]. Combining a nebulizer with an inhalation chamber may significantly increase lung doses, as suggested by the scintigraphic study by Harvey et al. [22] Actuating an MDI in an inhalation chamber placed at the Y-piece allowed a 1.5-fold to 4-fold increase in lung doses of bronchodilators [20,30].

The characteristics of mechanical ventilation during aerosol therapy are detailed in Additional file 2: Table S4. Most of the characteristics were not reported in a majority of studies. Only five clinical studies [14, 17, 18, 35, 49] reported all principal potential confounders, which was in contrast to all of the experimental studies. Lu et al. [49] standardized the administration technique to deliver inhaled antibiotics in 20 patients with VAP; a constantoutput vibrating-mesh nebulizer was placed on the inspiratory limb at $10 \mathrm{~cm}$ of the Y-piece, specific ventilator settings were used (tidal volume of $8 \mathrm{~mL} / \mathrm{kg}$, respiratory rate of $12 \mathrm{c} / \mathrm{min}$, duty cycle of $50 \%$, constant and low inspiratory flow rate inferior to $30 \mathrm{~L} / \mathrm{min}$ and endinspiratory pause of 20\%), and a heating-humidifier system was not used. but the heat and moisture exchanger filter was removed from the circuit during inhalation. Using this optimized technique, the authors observed 63\% ND reaching the inlet of the endotracheal tube based on 37\% ND extrapulmonary deposition. Among ventilationrelated factors, Dugernier et al. [18] demonstrated the benefit of volume-controlled ventilation to increase lung doses in comparison with a spontaneous breathing pattern in pressure support ( 15.1 vs $10.5 \% \mathrm{ND}, p<0.05)$. Miller et al. [31] measured a threefold increase in tracheobronchial concentrations of antibiotics when administrating the aerosol in a dry ventilator circuit instead of a heatedhumidified circuit $(8.1 \pm 1.5$ vs $2.2 \pm 0.4 \mu \mathrm{g} / \mathrm{mL} / \mathrm{mg}, p<$ 0.001 ). Using helium instead of nitrogen in inhaled gas was found to increase ceftazidime concentrations in subpleural lung specimens of healthy pigs from $383 \pm 84$ with $\mathrm{N}_{2}-\mathrm{O}_{2}$ to $576 \pm 141 \mu \mathrm{g} / \mathrm{g}$ with $\mathrm{He}-\mathrm{O}_{2}$. However, the concentrations were similar in infected lung segments whichever the inhaled gas [48].

\section{Discussion}

This article describes the first systematic review to evaluate in vivo deposition of aerosolized drugs during invasive mechanical ventilation. Lung deposition of $38 \%$ ND was reported with metered-dose inhalers which was not different from the doses reported in spontaneously breathing subjects [50]. However, lung deposition up to $16 \%$ ND was reported with nebulizers, which is likely impaired by inadequate administration techniques

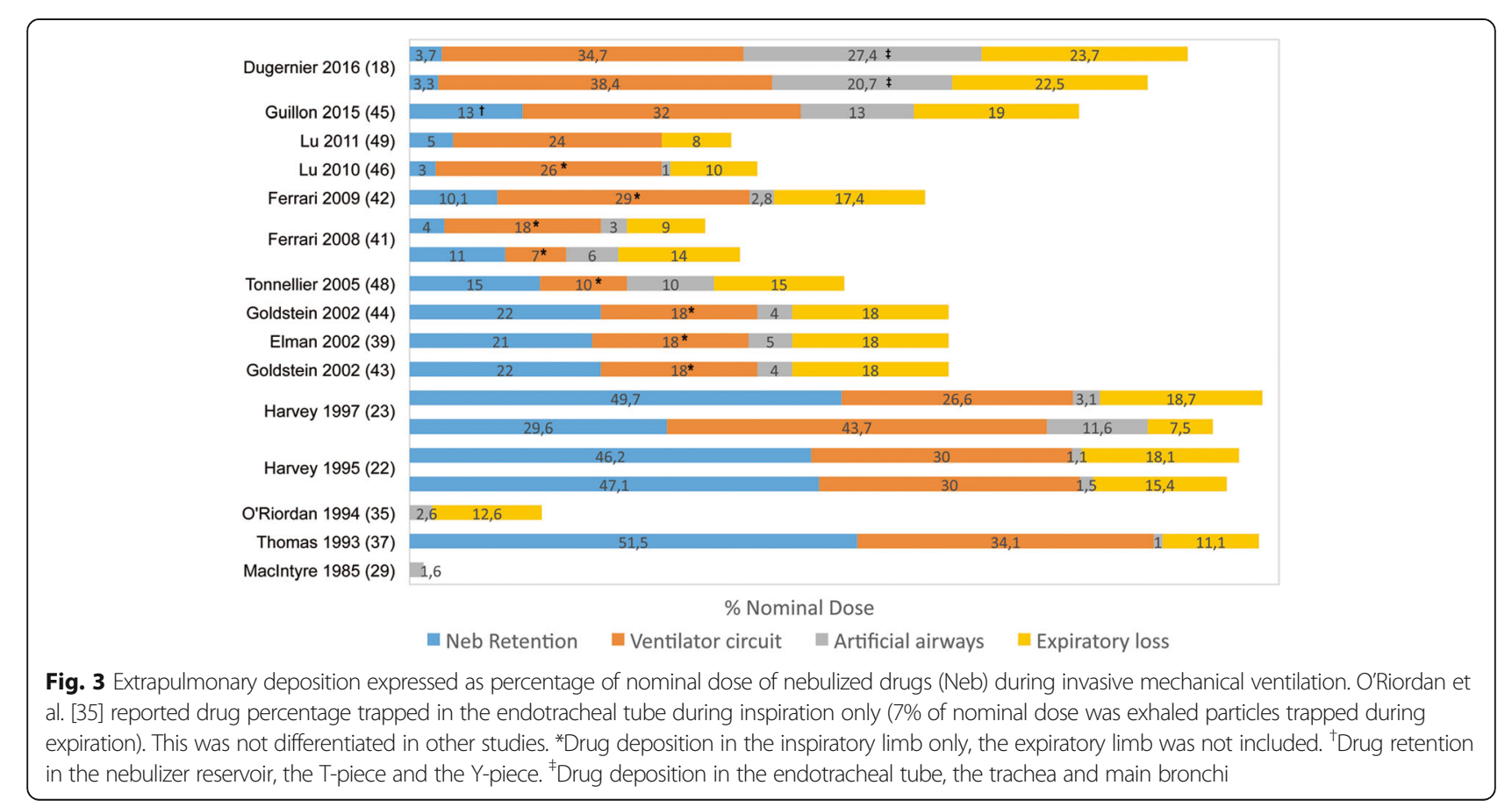


generating substantial aerosol loss in the ventilator circuit. Lung deposition was highly variable and mostly occurred in proximal airways, according to which type of device was used. Although the high concentrations of nebulized antibiotics measured in the ELF of infected patients (in comparison with the intravenous administration) suggested effective delivery to alveoli, the deposition in the distal lung parenchyma and different lung regions has never been quantified comprehensively in patients, especially in infected areas.

High inhaled doses (up to 66\% ND) were deducted from the mass balance technique [36, 39, 41, 42, 44-46, 48]. The ND of inhaled antibiotics suggested for the treatment of VAP is based on this proportion [49]. However, lung doses may be overestimated due to limitations inherent to the mass balance technique, which primarily include incomplete rinsing of the ventilator circuit and drug mass. The drug trickle from the artificial airways into the trachea can be quantified as having been delivered to the lungs. These overestimations may be substantial especially when the nebulizer is close to the patient (see Fig. 2).

There are reports from studies of measurements of 1 $-16 \%$ ND of drugs deposited in the lungs of ventilated patients with nebulizers [18-20, 22, 23, 29, 35, 37]. While efficient bronchodilation was observed with such doses [51, 52], reaching therapeutic levels of antibiotics may be more challenging. These values are low in comparison with that reported in spontaneously breathing patients using similar models of jet or vibrating-mesh nebulizer (15-35\% ND) [53-56]. Historically, mechanical ventilation has been considered to be a barrier to drug delivery $[17,29]$. However, lung deposition is conditioned by the administration technique. An important result of this review is that most in vivo deposition studies were performed before in vitro studies that assessed the factors influencing aerosol delivery during mechanical ventilation were performed. Those in vitro studies reported substantial inhaled doses with jet nebulizers (up to $45 \% \mathrm{ND}$ ) [57, 58], ultrasonic nebulizers (up to $25 \% \mathrm{ND}$ ) $[59,60]$ and vibrating-mesh nebulizers (up to $72 \% \mathrm{ND})[61-64]$.

The following five factors potentially explain the low drug deposition: the poor efficiency of jet nebulizers [19, 22, 23, 37] (ID from 10 to $15 \%$ ND reported in vitro $[58,65]$ ) or ultrasonic nebulizers with a voluminous reservoir [23] (ID of 15\% ND reported in vitro [60]), the inadequate position in the ventilator circuit increasing either deposition on the inspiratory limb when the nebulizer was placed too far away from the patient [19] or aerosol loss in the expiratory flow when the nebulizer was placed too close $[18,22$, 23, 25, 29, 37] (less than $15 \mathrm{~cm}$, even for inspiratory synchronized jet nebulizers considering the delayed synchronization reported in vitro [66]), the use of a heated-humidified ventilator circuit $[22,23,37]$ and the absence of standardized optimal ventilator settings. Furthermore, patient-related factors (e.g., COPD, ARDS, open-heart surgery) may also influence aerosol deposition $[19,22,23,29,37]$. O'Riordan et al. [35] optimized the administration technique using an inspiratory synchronized jet nebulizer, as determined in vitro $[31,57,58]$ and measured higher lung doses of radiolabeled drug delivered to ventilated patients than reported in other scintigraphic studies not implementing optimized techniques (15\% vs $1-3 \%$ ND) [19, 22, 23, 29, 35].

Although a homogeneous distribution between both lungs has been observed in ventilated patients with healthy lungs, there is a trend towards higher physiologic right lung deposition, as suggested in healthy volunteers $[67,68]$. Scintigraphic studies in critically ill patients [24] or patients undergoing open-heart surgery $[22,23,37]$ report higher right lung deposition, probably associated with impaired left lung ventilation. Scintigraphic studies report major deposition in proximal airways with penetration indexes below 1 and a greater proportion of radiolabeled drug deposited in the trachea and large bronchi [18, 24, 37].

The pathologic condition of the lung (secretion plugs or inflammatory condensation $[42,43,46,48]$, atelectasis [40], postoperative complication [22, 23, 37], or chest trauma [38]) alter aerosol distribution and penetration. As demonstrated by Elman et al. [39], the higher the aeration loss in a lung region, the lower the aerosol deposition. Aerosol penetration is also influenced by the particle size characterized by the median mass aerodynamic diameter (MMAD) [69]. However, the MMAD inferior to $3 \mu \mathrm{m}$ measured at the distal tip of the endotracheal tube in most studies supports good distal penetration of the aerosol $[18,23]$. High inspiratory flow promotes both turbulence and inertial impaction favoring particle deposition in the ventilator circuit and proximal airways, which reduces distal delivery [62]. Controlling and decreasing the inspiratory flow rate and reducing flow turbulence using lower density gases such as helium, reduces aerosol retention within the circuit in bench studies [62, 70, 71] and increases distal deposition in ventilated animals with healthy lungs $[48,72]$.

Aerosolized drugs may reach distal airways, as suggested by the higher antibiotic concentrations in dissected subpleural specimens from ventilated piglets (3-fold to 30fold) $[39,42-44,46]$ or in the ELF recovered from BAL in patients with VAP $[14,16,38]$ obtained using the inhalation route instead of the intravenous administration. The Pulmonary Drug Delivery System (PDDS, Nektar Therapeutics, San Carlos, CA, USA) is a recent inspiratory synchronized vibrating-mesh nebulizer specifically designed for amikacin sulfate delivery for the treatment of VAP. Two in vitro studies have demonstrated the accurate 
synchronization of the PDDS with inhaled dose from 50 to $72 \%$ ND $[63,64]$. Highly superior peak concentrations of amikacin were obtained in the tracheal secretions (2500-fold [34]) and the ELF (500-fold [27]) recovered from infected areas of VAP patients when compared with the intravenous administration [73, 74]. However, BAL fluid or endotracheal suctioning may both be contaminated by highly concentrated tracheobronchial secretions or particles impacted in the lumen of the artificial airways. No imaging data have been reported to confirm the better aerosol deposition with the inspiratory synchronized vibrating-mesh nebulizer compared with available nebulizers.

Clinicians should be aware of a high inter-subject variability of lung deposition in terms of lung doses, right and left lung distribution and penetration from the central airways to the lung periphery. Potential explanations include the fact that the MMAD differs between nebulizers of the same type and characterizes the deposited particle distribution through the airways [58, 75]. Moreover, patients themselves differ with respect to morphology, lung anatomy, lung pathology [76], and nonstandardized breathing patterns. However, in vitro studies demonstrated the variable inhaled doses while varying the respiratory rate, inspiratory time, inspiratory flow and the tidal volume [58,60,62, 65, 70]. The limitations of the deposition assessment methods may have also altered the measurements such as unstandardized lung outlines for scintigraphic analysis, BAL fluid or endotracheal suctioning sample contamination and mini-BAL measurements in different lung segments $[14,27,32,64]$.

The ventilator circuit $(10-43 \% \mathrm{ND})$ and, to a lesser extent, the artificial airways, filter a substantial fraction of emitted particles, as suggested by the higher MMAD measured at the outlet of the nebulizer than the MMAD at the distal tip of the endotracheal tube [23, 44]. When the nebulizer is positioned close to the patient, artificial airways trap a significant amount of particles. A small fraction of impacted particles remains in the internal lumen of the endotracheal tube whereas the majority trickles into the trachea (and the right main bronchi), as demonstrated by the $20-27 \%$ ND measured in these areas by Dugernier et al. [18] This phenomenon is important, as it may lead to major overestimation of aerosol lung delivery when estimated through the mass balance technique. In contrast, scintigraphic deposition studies enable correct visualization of the site of aerosol deposition.

Most studies have focused on inhaled antibiotics, which require a rigorous administration technique with nebulizers. Several methods to improve aerosol delivery to the lungs have been emphasized in this systematic review, as demonstrated in vitro (Table 3) [6]. In their phase II trial, Lu et al. [49] optimized the administration technique using a checklist form. The authors found interesting results in 20 patients with VAP receiving inhaled amikacin and ceftazidime alone without intravenous therapy in comparison to 20 patients with VAP receiving intravenous antibiotics. Similar clinical cure and superinfection rates with other microorganisms and successful treatment of patients infected with intermediate strains in the aerosol group, suggested efficient antibiotic delivery to the infected lung site [49]. No in vivo aerosol deposition evaluation was performed in this study to link the optimized aerosol technique to improved deposition and clinical outcome.

The administration technique varied greatly among all clinical studies that assessed lung deposition in vivo. Of note, the ventilator settings were not standardized and varied between patients in those studies, unlike in the study of Lu et al. [49]. Recent international surveys reported that recommendations to improve aerosol delivery are not regularly respected in current practice due to insufficient knowledge and the absence of a standardized protocol. $[1,77]$. Reviewing the administration technique raised limitations to apply the current scientific knowledge by investigators. Many factors influencing lung deposition with available nebulizers are difficult to control in routine practice such as financial concerns according to the type of nebulizer (e.g., jet nebulizers for antibiotic delivery), the ventilator settings necessary for adequate ventilation, sedative infusion to adapt the patient to the ventilator (especially for prolonged synchronized nebulization or frequent administrations), heatinghumidification of inhaled gases in patients with ARDS or COPD, expiratory loss due to the bias flow fixed by the manufacturer in most ventilators and high turbulent flows that induce inertial impactions in different components of the ventilator circuit, in the artificial airways and the trachea. The potential advantages of accurate synchronization (i.e., the closest position of the nebulizer to the patient) of emerging inspiratory synchronized vibrating-mesh nebulizers are several when compared with all available nebulizers: higher inhaled doses through

Table 3 Practical recommendations to improve inhaled drug deposition with nebulizers

Using vibrating-mesh nebulizers with minimal drug retention and no risk of protein denaturation as observed with ultrasonic nebulizers $[18,27,28,34,41]$

Promoting inspiratory synchronized nebulizers [27, 28, 31, 35]

Combining an inhalation chamber with constant-output nebulizers (to be confirmed in further studies) [22]

Generating aerosol particles in a dry circuit ${ }^{a}[31]$

Controlling the breathing pattern (high $\mathrm{T}_{\text {insp }} / \mathrm{T}_{\mathrm{TOT}}^{\mathrm{a}}$, low inspiratory flow) in volume control mode [18]

Using a helium-oxygen mixture as inhaled gas [48]

aprobably not relevant with a recent prototype of inspiratory synchronized vibrating-mesh nebulizer, as suggested by Luyt et al. [27] 
minimal impact on the ventilator circuit and minimal expiratory loss, ventilator compatibility (ventilator settings, bias flow, components of the circuit and heated humidification) and no need to disconnect the circuit (filter or nebulized removal) and hence, lower risk of alveolar derecruitment. These prototype inspiratory synchronized vibrating-mesh nebulizers may help to standardize an efficient, safe and feasible administration technique.

Future goals in this field include assessment of the intrapulmonary and extrapulmonary deposition to define and standardize the administration technique (i.e., whether it is necessary to adapt mechanical ventilation characteristics). Human lung deposition studies should be promoted as a "bridge" between in vitro and clinical efficacy studies [78]. While pharmacokinetics studies are limited to the assessment of whole lung deposition, scintigraphic studies may help to assess the deposition of the aerosol in different locations from the ventilator circuit to the patient. Combining a high-resolution computed tomography (CT) scan with SPECT-CT acquisitions may provide essential information on anatomical regional lung deposition (lobar analysis). However, the radioactivity exposure should be discussed [79]. Further studies are needed to test emerging devices (e.g., inspiratory synchronized nebulizers, dry powder inhalers and spacers), new drug formulations (e.g., inhalable liposome formulations or nanoparticles) and anti-infective agents (e.g., antibodies, phages). Studies aimed at developing personalized medicine may offer the possibility to confirm the ability to reach the distal airways, especially in the pathologic area (healthy vs infected lungs or focal vs diffuse infections).

This systematic review has several limitations inherent to the heterogeneity of the studies. First, comparing lung delivery rates among studies is complicated due to variable characteristics known to influence aerosol delivery: the population (human vs animal, healthy lung vs pathologic change in the lung), the aerosol device, the aerodynamic or physicochemical properties of inhaled drugs and the deposition assessment methods [6, 76]. Mechanical ventilation characteristics varied also among studies due to the evolution in the management of mechanically ventilated patients (ventilator settings and circuit) during the last 30 years and the absence of a standardized delivery technique. Second, the results from studies with small sample sizes are highly sensitive to confounding factors. The confounders were partially described and most studies did not calculate the needed sample size. The small sample size of the studies included in this review may have contributed to the variability in lung deposition observed in addition to these confounders.

\section{Conclusions}

Aerosol delivery to mechanically ventilated patients has improved throughout the years. However, lung depositions lower than 20\% ND were reported with nebulizers due to suboptimal conditions of administration that induced high aerosol loss in the ventilator circuit given that most deposition studies did not incorporate scientific knowledge subsequently gained from in vitro studies. Moreover, most studies revealed highly variable lung deposition rates in terms of doses and locations. Several factors related to the subject or mechanical ventilation that cannot be controlled probably account for this heterogeneity in part. The administration technique with nebulizers should be improved in ventilated patients with the final goal to ensure an efficient but safe, feasible and reproducible technique. Modern optimized nebulization techniques should be tested using imaging techniques to confirm the substantial distal deposition, even in infected lung areas, as reported in pharmacokinetics studies and suggested in clinical phase II studies.

\section{Additional files}

Additional file 1: Complementary information related to the search strategy, selection criteria, data extraction and data expression. It also includes the full electronic search strategy (detailed search equation) for the Pubmed database. (DOCX 55 kb)

Additional file 2: Table S1. Characteristics and results of the clinical studies. Table S2. Characteristics and results of the experimental studies. Table S3. Downs and Black score of the included studies. Table S4. Mechanical ventilation characteristics during inhalation. (DOCX 209 kb)

\begin{abstract}
Abbreviations
\%ID: Percentage of inhaled dose; \%ND: Percentage of nominal dose; ARDS: Acute respiratory distress syndrome; BAL: Bronchoalveolar lavage; COPD: Chronic obstructive pulmonary disease; CV: Coefficient of variation; ELF: Epithelial lining fluid; ID: Inhaled dose; MDI: Metered-dose inhaler; MMAD: Mass median aerodynamic diameter; ND: Nominal dose; PDDS: Pulmonary Drug Delivery System; PSV: Pressure support ventilation; SPECT-CT: Single photon emission tomography combined with a computed tomography scanner; VAP: Ventilator-associated pneumonia; VAT: Ventilatorassociated tracheobronchitis; VCV: Volume controlled ventilation
\end{abstract}

\section{Acknowledgements}

The authors acknowledge the editorial assistance provided by Mrs Carline Dugernier.

Funding

This study did not receive funds.

\section{Availability of data and materials}

All data generated or analyzed during this study are included in this published article and its supplementary information files.

\section{Authors' contributions}

Data collection, JD and GR; study design, JD and GR; data analysis, JD, GR, SE and TD, manuscript preparation, JD, GR, SE, TD, TS, FJ, PFL and JR; review of the manuscript, JD, GR, TD, TS, FJ, SE, PFL, JR and XW. All authors read and approved the final manuscript.

Ethics approval and consent to participate Not applicable.

Consent for publication Not applicable. 


\section{Competing interests}

The authors declare that they have no competing interests. Stephan Ehrmann received research support to his institution from Aerogen Ltd, Fisher \& Paykel and Hamilton Medical and consultancies/lecture fees from Aerogen Ltd, La diffusion technique Française.

\section{Publisher's Note}

Springer Nature remains neutral with regard to jurisdictional claims in published maps and institutional affiliations.

\section{Author details}

${ }^{1}$ Institut de Recherche Expérimentale et Clinique (IREC), Pneumologie, ORL \& Dermatologie, Cliniques universitaires Saint-Luc, Avenue Hippocrate 10, 1200 Brussels, Belgium. ${ }^{2}$ Soins Intensifs, Cliniques universitaires Saint-Luc, Avenue Hippocrate 10, 1200 Brussels, Belgium. ${ }^{3}$ Médecine Physique, Cliniques universitaires Saint-Luc, Avenue Hippocrate 10, 1200 Brussels, Belgium. ${ }^{4}$ Université François Rabelais, UMR 1100, F-37032 Tours, France. ${ }^{5}$ INSERM, Centre d'étude des Pathologies Respiratoires, UMR 1100, F-37032 Tours, France. ${ }^{6} \mathrm{CHRU}$ de Tours, Réanimation polyvalente, F-37044 Tours, France. ${ }^{7}$ Soins Intensifs, Clinique Notre-Dame de Grace, Chaussée de Nivelles 212, 6041 Charleroi, Belgium. ${ }^{8}$ Soins Intensifs, Clinique Saint-Pierre, Avenue Reine Fabiola 9, 1340 Ottignies, Belgium. ${ }^{9}$ Médecine Nucléaire, Cliniques universitaires Saint-Luc, Avenue Hippocrate 10, 1200 Brussels, Belgium.

${ }^{10}$ Pneumologie, Cliniques universitaires Saint-Luc, Avenue Hippocrate 10, 1200 Brussels, Belgium.

\section{Received: 25 April 2017 Accepted: 15 September 2017}

\section{Published online: 21 October 2017}

\section{References}

1. Ehrmann S, Roche-Campo F, Sferrazza Papa GF, Isabey D, Brochard L, ApiouSbirlea G, et al. Aerosol therapy during mechanical ventilation: an international survey. Intensive Care Med. 2013;39(6):1048-56.

2. Dhand R, Tobin MJ. Inhaled bronchodilator therapy in mechanically ventilated patients. Am J Respir Crit Care Med. 1997;156(1):3-10.

3. Mouloudi E, Katsanoulas K, Anastasaki M, Hoing S, Georgopoulos D. Bronchodilator delivery by metered-dose inhaler in mechanically ventilated COPD patients: influence of tidal volume. Intensive Care Med. 1999;25(11): 1215-21.

4. Bassetti M, Luyt CE, Nicolau DP, Pugin J. Characteristics of an ideal nebulized antibiotic for the treatment of pneumonia in the intubated patient. Ann Intensive Care. 2016;6(1):35.

5. Dhand R. Aerosol delivery during mechanical ventilation: from basic techniques to new devices. J Aerosol Med Pulm Drug Deliv. 2008;21(1):45-60

6. Ari A. Aerosol therapy in pulmonary critical care. Respir Care. 2015;60(6): 858-74. discussion 74-9.

7. Ari A, Fink JB. Factors affecting bronchodilator delivery in mechanically ventilated adults. Nurs Crit Care. 2010;15(4):192-203.

8. Dhand R, Guntur VP. How best to deliver aerosol medications to mechanically ventilated patients. Clin Chest Med. 2008;29(2):277-96. vi.

9. Dhanani J, Fraser JF, Chan HK, Rello J, Cohen J, Roberts JA. Fundamentals of aerosol therapy in critical care. Crit Care. 2016;20(1):269.

10. Rouby JJ, Bouhemad B, Monsel A, Brisson H, Arbelot C, Lu Q, et al. Aerosolized antibiotics for ventilator-associated pneumonia: lessons from experimental studies. Anesthesiology. 2012;117(6):1364-80.

11. Moher D, Liberati A, Tetzlaff J, Altman DG, Group P. Preferred reporting items for systematic reviews and meta-analyses: the PRISMA statement. PLoS Med. 2009;6(7), e1000097.

12. Downs SH, Black N. The feasibility of creating a checklist for the assessment of the methodological quality both of randomised and non-randomised studies of health care interventions. J Epidemiol Community Health. 1998; 52(6):377-84.

13. Newman S, Bennett WD, Biddiscombe M, Devadason SG, Dolovich MB, Fleming J, et al. Standardization of techniques for using planar (2D) imaging for aerosol deposition assessment of orally inhaled products. J Aerosol Med Pulm Drug Deliv. 2012;25 Suppl 1:S10-28.

14. Athanassa ZE, Markantonis SL, Fousteri MZ, Myrianthefs PM, Boutzouka EG, Tsakris A, et al. Pharmacokinetics of inhaled colistimethate sodium (CMS) in mechanically ventilated critically ill patients. Intensive Care Med. 2012;38(11): 1779-86.
15. Badia JR, Soy D, Adrover M, Ferrer M, Sarasa M, Alarcon A, et al. Disposition of instilled versus nebulized tobramycin and imipenem in ventilated intensive care unit (ICU) patients. J Antimicrob Chemother. 2004:54(2):508-14.

16. Boisson M, Jacobs M, Gregoire N, Gobin P, Marchand S, Couet W, et al. Comparison of intrapulmonary and systemic pharmacokinetics of colistin methanesulfonate (CMS) and colistin after aerosol delivery and intravenous administration of CMS in critically ill patients. Antimicrob Agents Chemother. 2014;58(12):7331-9.

17. Duarte AG, Dhand R, Reid R, Fink JB, Fahey PJ, Tobin MJ, et al. Serum albuterol levels in mechanically ventilated patients and healthy subjects after metered-dose inhaler administration. Am J Respir Crit Care Med. 1996; 154(6 Pt 1):1658-63.

18. Dugernier J, Reychler G, Wittebole X, Roeseler J, Depoortere V, Sottiaux T, et al. Aerosol delivery with two ventilation modes during mechanical ventilation: a randomized study. Ann Intensive Care. 2016;6(1):73.

19. Fuller HD, Dolovich MB, Posmituck G, Pack WW, Newhouse MT. Pressurized aerosol versus jet aerosol delivery to mechanically ventilated patients. Comparison of dose to the lungs. Am Rev Respir Dis. 1990;141(2):440-4.

20. Fuller HD, Dolovich MB, Turpie FH, Newhouse MT. Efficiency of bronchodilator aerosol delivery to the lungs from the metered dose inhaler in mechanically ventilated patients. A study comparing four different actuator devices. Chest. 1994;105(1):214-8.

21. Girard PM, Clair B, Certain A, Bidault R, Matheron S, Regnier B, et al. Comparison of plasma concentrations of aerosolized pentamidine in nonventilated and ventilated patients with pneumocystosis. Am Rev Respir Dis. 1989;140(6):1607-10.

22. Harvey CJ, O'Doherty MJ, Page CJ, Thomas SH, Nunan TO, Treacher DF. Effect of a spacer on pulmonary aerosol deposition from a jet nebuliser during mechanical ventilation. Thorax. 1995;50(1):50-3.

23. Harvey CJ, O'Doherty MJ, Page CJ, Thomas SH, Nunan TO, Treacher DF. Comparison of jet and ultrasonic nebulizer pulmonary aerosol deposition during mechanical ventilation. Eur Respir J. 1997:10(4):905-9.

24. Klockare M, Dufva A, Danielsson AM, Hatherly R, Larsson S, Jacobsson H, et al. Comparison between direct humidification and nebulization of the respiratory tract at mechanical ventilation: distribution of saline solution studied by gamma camera. J Clin Nurs. 2006;15(3):301-7.

25. Le Conte P, Potel G, Peltier P, Horeau D, Caillon J, Juvin ME, et al. Lung distribution and pharmacokinetics of aerosolized tobramycin. Am Rev Respir Dis. 1993;147(5):1279-82.

26. Lee YH, Kwon GY, Park DY, Bang JY, Jang DM, Lee SH, et al. Efficiency of a new mesh-type nebulizer (NE-SM1 NEPLUS) for intrapulmonary delivery of ipratropium bromide in surgical patients. Basic Clin Pharmacol Toxicol. 2016; 118(4):313-9.

27. Luyt CE, Clavel M, Guntupalli K, Johannigman J, Kennedy J, Wood C, et al. Pharmacokinetics and lung delivery of PDDS-aerosolized amikacin (NKTR061) in intubated and mechanically ventilated patients with nosocomial pneumonia. Crit Care. 2009;13(6):R200.

28. Luyt CE, Eldon MA, Stass H, Gribben D, Corkery K, Chastre J. Pharmacokinetics and tolerability of amikacin administered as BAY41-6551 aerosol in mechanically ventilated patients with gram-negative pneumonia and acute renal failure. J Aerosol Med Pulm Drug Deliv. 2011;24(4):183-90.

29. Macintyre NR, Silver RM, Miller CW, Schuler F, Coleman RE. Aerosol delivery in intubated, mechanically ventilated patients. Crit Care Med. 1985;13(2):81-4.

30. Marik P, Hogan J, Krikorian J. A comparison of bronchodilator therapy delivered by nebulization and metered-dose inhaler in mechanically ventilated patients. Chest. 1999;115(6):1653-7.

31. Miller DD, Amin MM, Palmer LB, Shah AR, Smaldone GC. Aerosol delivery and modern mechanical ventilation: in vitro/in vivo evaluation. Am J Respir Crit Care Med. 2003;168(10):1205-9.

32. Montgomery AB, Vallance $\mathrm{S}$, Abuan $\mathrm{T}$, Tservistas M, Davies A. A randomized double-blind placebo-controlled dose-escalation phase 1 study of aerosolized amikacin and fosfomycin delivered via the PARI investigational eFlow(R) inline nebulizer system in mechanically ventilated patients. J Aerosol Med Pulm Drug Deliv. 2014;27(6):441-8.

33. Moraine JJ, Truflandier K, Vandenbergen N, Berre J, Melot C, Vincent JL. Placement of the nebulizer before the humidifier during mechanical ventilation: effect on aerosol delivery. Heart Lung. 2009;38(5):435-9.

34. Niederman MS, Chastre J, Corkery K, Fink JB, Luyt CE, Garcia MS. BAY41-6551 achieves bactericidal tracheal aspirate amikacin concentrations in mechanically ventilated patients with Gram-negative pneumonia. Intensive Care Med. 2012; 38(2):263-71. 
35. O'Riordan TG, Palmer LB, Smaldone GC. Aerosol deposition in mechanically ventilated patients. Optimizing nebulizer delivery. Am J Respir Crit Care Med. 1994;149(1):214-9.

36. Palmer LB, Smaldone GC, Simon SR, O'Riordan TG, Cuccia A. Aerosolized antibiotics in mechanically ventilated patients: delivery and response. Crit Care Med. 1998;26(1):31-9.

37. Thomas SH, O'Doherty MJ, Fidler HM, Page CJ, Treacher DF, Nunan TO. Pulmonary deposition of a nebulised aerosol during mechanical ventilation. Thorax. 1993;48(2):154-9.

38. Wood GC, Boucher BA, Croce MA, Hanes SD, Herring VL, Fabian TC. Aerosolized ceftazidime for prevention of ventilator-associated pneumonia and drug effects on the proinflammatory response in critically ill trauma patients. Pharmacotherapy. 2002;22(8):972-82.

39. Elman M, Goldstein I, Marquette CH, Wallet F, Lenaour G, Rouby JJ, et al. Influence of lung aeration on pulmonary concentrations of nebulized and intravenous amikacin in ventilated piglets with severe bronchopneumonia Anesthesiology. 2002;97(1):199-206

40. Ferrari F, Goldstein I, Nieszkowszka A, Elman M, Marquette CH, Rouby JJ, et al. Lack of lung tissue and systemic accumulation after consecutive daily aerosols of amikacin in ventilated piglets with healthy lungs. Anesthesiology. 2003;98(4):1016-9.

41. Ferrari F, Liu ZH, Lu Q, Becquemin MH, Louchahi K, Aymard G, et al. Comparison of lung tissue concentrations of nebulized ceftazidime in ventilated piglets: ultrasonic versus vibrating plate nebulizers. Intensive Care Med. 2008;34(9):1718-23.

42. Ferrari F, Lu Q, Girardi C, Petitjean O, Marquette CH, Wallet F, et al. Nebulized ceftazidime in experimental pneumonia caused by partially resistant Pseudomonas aeruginosa. Intensive Care Med. 2009;35(10):1792800.

43. Goldstein I, Wallet F, Nicolas-Robin A, Ferrari F, Marquette CH, Rouby JJ. Lung deposition and efficiency of nebulized amikacin during Escherichia coli pneumonia in ventilated piglets. Am J Respir Crit Care Med. 2002; 166(10):1375-81.

44. Goldstein I, Wallet F, Robert J, Becquemin MH, Marquette $\mathrm{CH}$, Rouby JJ. Lung tissue concentrations of nebulized amikacin during mechanical ventilation in piglets with healthy lungs. Am J Respir Crit Care Med. 2002; 165(2):171-5.

45. Guillon A, Mercier E, Lanotte P, Haquenoer E, Darrouzain F, Barc C, et al. Aerosol route to administer teicoplanin in mechanical ventilation: in vitro study, lung deposition and pharmacokinetic analyses in pigs. J Aerosol Med Pulm Drug Deliv. 2015;28(4):290-8.

46. Lu Q, Girardi C, Zhang M, Bouhemad B, Louchahi K, Petitjean O, et al. Nebulized and intravenous colistin in experimental pneumonia caused by Pseudomonas aeruginosa. Intensive Care Med. 2010;36(7):1147-55.

47. Selting K, Waldrep JC, Reinero C, Branson K, Gustafson D, Kim DY, et al. Feasibility and safety of targeted cisplatin delivery to a select lung lobe in dogs via the AeroProbe intracorporeal nebulization catheter. J Aerosol Med Pulm Drug Deliv. 2008;21(3):255-68

48. Tonnellier M, Ferrari F, Goldstein I, Sartorius A, Marquette CH, Rouby JJ. Intravenous versus nebulized ceftazidime in ventilated piglets with and without experimental bronchopneumonia: comparative effects of helium and nitrogen. Anesthesiology. 2005;102(5):995-1000.

49. Lu Q, Yang J, Liu Z, Gutierrez C, Aymard G, Rouby JJ, et al. Nebulized ceftazidime and amikacin in ventilator-associated pneumonia caused by Pseudomonas aeruginosa. Am J Respir Crit Care Med. 2011;184(1):106-15.

50. Moore A, Riddell K, Joshi S, Chan R, Mehta R. Pharmacokinetics of salbutamol delivered from the unit dose dry powder inhaler: comparison with the metered dose inhaler and Diskus dry powder inhaler. J Aerosol Med Pulm Drug Deliv. 2017;30(3):164-72.

51. Dhand R, Jubran A, Tobin MJ. Bronchodilator delivery by metered-dose inhaler in ventilator-supported patients. Am J Respir Crit Care Med. 1995; 151(6):1827-33.

52. Gay PC, Patel HG, Nelson SB, Gilles B, Hubmayr RD. Metered dose inhalers for bronchodilator delivery in intubated, mechanically ventilated patients. Chest. 1991;99(1):66-71.

53. Coates AL, Denk O, Leung K, Ribeiro N, Chan J, Green M, et al. Higher tobramycin concentration and vibrating mesh technology can shorten antibiotic treatment time in cystic fibrosis. Pediatr Pulmonol. 2011;46(4):401-8.

54. Coates AL, Green M, Leung K, Chan J, Ribeiro N, Louca E, et al. Rapid pulmonary delivery of inhaled tobramycin for Pseudomonas infection in cystic fibrosis: a pilot project. Pediatr Pulmonol. 2008;43(8):753-9.
55. Coates AL, Green M, Leung K, Chan J, Ribeiro N, Ratjen F, et al. A comparison of amount and speed of deposition between the PARI LC STAR(R) jet nebulizer and an investigational eflow(R) nebulizer. J Aerosol Med Pulm Drug Deliv. 2011;24(3):157-63.

56. Dugernier J, Hesse M, Vanbever R, Depoortere V, Roeseler J, Michotte JB, et al. SPECT-CT comparison of lung deposition using a system combining a vibrating-mesh nebulizer with a valved holding chamber and a conventional jet nebulizer: a randomized cross-over study. Pharm Res. 2017; 34(2):290-300.

57. Diot P, Morra L, Smaldone GC. Albuterol delivery in a model of mechanical ventilation. Comparison of metered-dose inhaler and nebulizer efficiency. Am J Respir Crit Care Med. 1995;152(4 Pt 1):1391-4.

58. O'Riordan TG, Greco MJ, Perry RJ, Smaldone GC. Nebulizer function during mechanical ventilation. Am Rev Respir Dis. 1992;145(5):1117-22.

59. Ari A, Areabi H, Fink JB. Evaluation of aerosol generator devices at 3 locations in humidified and non-humidified circuits during adult mechanica ventilation. Respir Care. 2010;55(7):837-44.

60. Thomas SH, O'Doherty MJ, Page CJ, Treacher DF, Nunan TO. Delivery of ultrasonic nebulized aerosols to a lung model during mechanical ventilation. Am Rev Respir Dis. 1993;148(4 Pt 1):872-7.

61. Ari A, Atalay OT, Harwood R, Sheard MM, Aljamhan EA, Fink JB. Influence of nebulizer type, position, and bias flow on aerosol drug delivery in simulated pediatric and adult lung models during mechanical ventilation. Respir Care. 2010;55(7):845-51.

62. Dugernier J, Wittebole X, Roeseler J, Michotte JB, Sottiaux T, Dugernier T, et al. Influence of inspiratory flow pattern and nebulizer position on aerosol delivery with a vibrating-mesh nebulizer during invasive mechanical ventilation: an in vitro analysis. J Aerosol Med Pulm Drug Deliv. 2015;28(3): 229-36

63. Fink JB, Dunne P, Mac Loughlin R, O'Sullivan G. Can high efficiency aerosol delivery continue after extubation? Crit Care. 2005;9(Supp 1):129.

64. Kadrichu N, Boc S, Corkery K, Challoner P. In vitro efficiency of Amikacin Inhale, a novel drug-device delivery system. Crit Care. 2013;17(Supp 2):81.

65. O'Doherty MJ, Thomas SH, Page CJ, Treacher DF, Nunan TO. Delivery of a nebulized aerosol to a lung model during mechanical ventilation. Effect of ventilator settings and nebulizer type, position, and volume of fill. Am Rev Respir Dis. 1992;146(2):383-8.

66. Ehrmann S, Lyazidi A, Louis B, Isabey D, Le Pennec D, Brochard L, et al. Ventilator-integrated jet nebulization systems: tidal volume control and efficiency of synchronization. Respir Care. 2014;59(10):1508-16.

67. Majoral C, Fleming J, Conway J, Katz I, Tossici-Bolt L, Pichelin M, et al. Controlled, parametric, individualized, 2D and 3D imaging measurements of aerosol deposition in the respiratory tract of healthy human volunteers: in vivo data analysis. J Aerosol Med Pulm Drug Deliv. 2014;27(5):349-62.

68. Fleming J, Conway J, Majoral C, Tossici-Bolt L, Katz I, Caillibotte G, et al. The use of combined single photon emission computed tomography and $\mathrm{X}$-ray computed tomography to assess the fate of inhaled aerosol. J Aerosol Med Pulm Drug Deliv. 2011;24(1):49-60.

69. Carvalho TC, Peters JI. Williams 3rd RO. Influence of particle size on regional lung deposition-what evidence is there? Int J Pharm. 2011:406(1-2):1-10.

70. Fink JB, Dhand R, Duarte AG, Jenne JW, Tobin MJ. Aerosol delivery from a metered-dose inhaler during mechanical ventilation. An in vitro model. Am J Respir Crit Care Med. 1996:154(2 Pt 1):382-7.

71. Goode ML, Fink JB, Dhand R, Tobin MJ. Improvement in aerosol delivery with helium-oxygen mixtures during mechanical ventilation. Am J Respir Crit Care Med. 2001;163(1):109-14.

72. Dahlback M, Wollmer $P$, Jonson B. Selective deposition of inhaled aerosols to mechanically ventilated rabbits. J Aerosol Med. 1994;7(4):315-24.

73. Santre C, Georges H, Jacquier JM, Leroy O, Beuscart C, Buguin D, et al. Amikacin levels in bronchial secretions of 10 pneumonia patients with respiratory support treated once daily versus twice daily. Antimicrob Agents Chemother. 1995;39(1):264-7.

74. Rodvold KA, George JM, Yoo L. Penetration of anti-infective agents into pulmonary epithelial lining fluid: focus on antibacterial agents. Clin Pharmacokinet. 2011;50(10):637-64

75. Sagalla RB, Smaldone GC. Capturing the efficiency of vibrating mesh nebulizers: minimizing upper airway deposition. J Aerosol Med Pulm Drug Deliv. 2014:27(5):341-8.

76. Thomas SH, O'Doherty MJ, Page CJ, Nunan TO. Variability in the measurement of nebulized aerosol deposition in man. Clin Sci (Lond). 1991. $81(6): 767-75$ 
77. Ehrmann S, Roche-Campo F, Bodet-Contentin L, Razazi K, Dugernier J, Trenado-Alvarez J, et al. Aerosol therapy in intensive and intermediate care units: prospective observation of 2808 critically ill patients. Intensive Care Med. 2016;42(2):192-201.

78. Newman SP, Wilding IR, Hirst PH. Human lung deposition data: the bridge between in vitro and clinical evaluations for inhaled drug products? Int J Pharm. 2000;208(1-2):49-60

79. Fleming J, Bailey DL, Chan HK, Conway J, Kuehl PJ, Laube BL, et al. Standardization of techniques for using single-photon emission computed tomography (SPECT) for aerosol deposition assessment of orally inhaled products. J Aerosol Med Pulm Drug Deliv. 2012;25 Suppl 1:S29-51.

Submit your next manuscript to BioMed Central and we will help you at every step:

- We accept pre-submission inquiries

- Our selector tool helps you to find the most relevant journal

- We provide round the clock customer support

- Convenient online submission

- Thorough peer review

- Inclusion in PubMed and all major indexing services

- Maximum visibility for your research

Submit your manuscript at www.biomedcentral.com/submit
Biomed Central 